\title{
Analysis of Divergent Thinking in Indian Engineering Students
}

\author{
V. Mahesh ${ }^{1}$, P.V. Raja Shekar ${ }^{2}$ and P. Pramod Kumar \\ ${ }^{1}$ Dept. of Mechanical Engineering, ${ }^{2}$ Dept. of Physics, ${ }^{3}$ Dept. of Computer Science and Engineering, \\ SR Engineering College, Warangal, Telangana, India \\ v.mahesh2@gmail.com¹,pvrsleo@gmail.com²,pramod1217@yahoo.com³
}

\begin{abstract}
Divergent thinking (DT) is one of the design skills which helps in generation of alternative design solutions for any given design task and is very much essential for addressing a design problem. Hence, an attempt has been made to evaluate the DT skills of Indian engineering students. The level of design fixation is also determined. The methodology of the work carried out to estimate and analyze DT skills and the results obtained are discussed in detail. The results throw light on the design skills of Indian engineering students, which perhaps help in the development of effective teaching methods.
\end{abstract}

Keywords - Design Skills; Divergent Thinking; Design Fixation

\section{Mahesh}

Dept. of Mechanical Engineering,

SR Engineering College, Warangal, Telangana, India v.mahesh2@gmail.com

\section{Introduction}

Designing is considered to be one of the most challenging and important human activities; it is complex, requires high intelligence and skills. "Everything that is absorbed and registered in the mind adds to the collection of ideas stored in the memory: a sort of library that can be consulted whenever a problem arises. So, essentially the more you have seen, experienced, and absorbed, the more points of reference you will have" [1]. The above statement is true in the context of engineering design, where the field has changed from a design scratch to a design-through-synthesis mindset, where designers transform, combine, or adapt elements of previous or existing designs to synthesize novel concepts [2]. However, designers often get fixated, termed as "design fixation" (designers' reluctance to consider multiple strategies to formulate and solve a design problem), hence one needs to understand and judge the fixation levels as well. A survey of literature suggests the following various design skills: divergent thinking, convergent thinking, deductive, inductive, and abductive reasoning, spatial reasoning, visual thinking, analogical reasoning, sketching, qualitative reasoning, decision-framing and decision making, and designing and conducting simulated or real experiments [3-5].

The motivation for the present work is derived from the work of Shah et al. [3-5], wherein the authors have taken up divergent thinking (DT), which is one of the design skills. It is well known that divergent thinking is a method or process of thinking that aims to 
develop a lot of ideas about a single topic in a relatively short span of time. It is a creative approach to problem solving. However, a detailed assessment of DT can be made with the help of a DT test, which is a most important tool to measure design skills. The subskills studied in the present work are similar to that of Shah et al. [3-5]. However, the experimental framework and the sample size are different from that of the earlier reports [3-5], which are discussed in the subsequent sections.

In the present paper, the methodology of the work carried out on DT in Indian engineering students and the results obtained are discussed in detail in the following sections. The work carried out by the authors can throw light on the design skills of Indian engineering students, henceforth leading to development of effective teaching methods as well as product development methods.

\section{Methodology}

\section{A. Measures of DT}

The DT sub-skills, their definitions, and measures are listed in Table 1, which is self-explanatory. Direct measures are ones that can be assessed from a set of ideas generated by an individual. Indirect measures are those that are assumed to aid ideation.

It is a common practice to use fluency as a measure of DT. However by doing this one cannot get all the information that is needed to measure design skills as it only gives information about the ability to explore design space. It does not speak anything about to what extent has the design space been explored i.e., the conceptual distance between the ideas and the quality of ideas generated.

Therefore in order to measure design skills one needs to measure about,

1) ability to define the design space

2) ability to explore the design space

3) ability to expand the design space

4) ability to avoid fixation

Ability to avoid fixation is one of the most important measures because the other three abilities are directly influenced by it. Design fixation is an undesired phenomenon, which has a negative impact on the design skills. It inhibits the thought process and cripples the designer's ability to explore and expand the design space.
Table 1. Dt Sub-skills And Metrics [3]

\begin{tabular}{|c|l|l|l|}
\hline $\begin{array}{c}\text { S. } \\
\text { No. }\end{array}$ & Sub-skill & \multicolumn{1}{|c|}{ Definition } & Metric \\
\hline \multicolumn{3}{|c|}{ Direct Measures } \\
\hline 1 & Fluency & $\begin{array}{l}\text { Ability to generate } \\
\text { many solutions } \\
\text { consistently }\end{array}$ & $\begin{array}{l}\text { Quantity of ideas } \\
\text { generated }\end{array}$ \\
\hline 3 & Flexibility & $\begin{array}{l}\text { Ability to explore } \\
\text { design space in } \\
\text { many directions }\end{array}$ & $\begin{array}{l}\text { Variety of ideas } \\
\text { generated }\end{array}$ \\
\hline 4 & Originality & $\begin{array}{l}\text { Ability to "think } \\
\text { outside the box," } \\
\text { generate unexpected } \\
\text { solutions }\end{array}$ & $\begin{array}{l}\text { Originality of ideas } \\
\text { generated }\end{array}$ \\
\hline 5 & Afixability & $\begin{array}{l}\text { Indirect Measures } \\
\text { ruts, not get fixated } \\
\text { to past or current } \\
\text { solutions }\end{array}$ & $\begin{array}{l}\text { Conceptual distance } \\
\text { from exposed } \\
\text { example }\end{array}$ \\
\hline & Detailability & $\begin{array}{l}\text { Ability to think at } \\
\text { detailed level }\end{array}$ & $\begin{array}{l}\text { Elaboration, } \\
\text { embellishments, } \\
\text { clarity }\end{array}$ \\
\hline & $\begin{array}{l}\text { Ability to make } \\
\text { connections, find } \\
\text { relationships, } \\
\text { analogies }\end{array}$ & $\begin{array}{l}\text { Number and } \\
\text { remoteness of } \\
\text { discovered relations }\end{array}$ \\
\hline
\end{tabular}

B. Sample and Size

The participants are primarily freshmen and senior students of the undergraduate engineering programme. The task has been conducted in different Institutes / Universities across India which includes IIT Kharagpur, JNTU Kakinada, Andhra University Vizag, GITAM University Vizag and SR Engineering College Warangal. A Prior permission has been taken from the above institutes and also a consent letter was taken from all the participants. Sufficient care has been taken while choosing the sample viz. 1) the sample size is at least 30 in each institute, 2) the sample consisted of both boys and girls of approximately same numbers, 3 ) the sample consisted freshmen and seniors of all disciplines and 4) the participants did not have prior knowledge of the design task conducted.

\section{Design Task and Conditions}

To assess the DT skill among the students, the following tasks are provided to them under the conditions discussed herewith. All the activities / tasks were performed individually and are independent of discipline. Further, the participants were directed to provide as many solutions as possible within the stipulated time. The DT test is conducted in two parts as follows:

The first part has 3 tasks and needs to be completed 
within 15 minutes. It measures DT skills such as fluency, flexibility, originality, abstractability and detailability. The first task (i.e. the circles task) helps in assessing fluency, flexibility, originality and detailability. In this task students are provided with a group of circles and are asked to draw as many meaningful figures as they can which have a circle as an integral element. The second task which is also a non-technical one, asks the students to list alternative or unusual uses of a day to day items / artifacts like water bottle, tissue paper etc. In addition to fluency, flexibility, originality, detailability, we can also access quality of ideas in this task. The third task was designed to assess abstractability, wherein the students were asked to list the similarities between abstract items that are listed therein.

The second part was designed specially to measure the design fixation, which has only one task and has to be completed within 20 minutes. In this, to assess the level of fixation, a simple design exercise, "design toy for a blind child of age group 3 to 7 years" was administered to students. The students were divided into two groups viz. control group and fixation group. The control group was provided with only the design task, while the fixation group was provided with an example solution to the design task. The data from the control group was used to set a baseline for measuring the level of fixation. The level of fixation was assessed by comparing the similarities between the solution provided by the student and the solution in the example. This design task is not only easy to comprehend but also domain independent to a large extent. It can be administered to freshmen \& seniors alike. At the end of this task, participants were asked to mention their favorite toy / last toy with which they played in order to find the inherent fixation level.

\section{Creativity Tests and Scoring Methods}

Creativity is defined as the production of novel and practical solutions to a design problem [6]. To be creative one must have the ability to explore the design space from various standpoints. Creative thinking tests measures not only the number of new possibilities that people produce but also the novelty of these possibilities [7]. Of the various standardized tests of creativity available in the literature, the authors have considered Abbreviated Torrance test, Guilford Alternative Uses test and Meekers test to assess the sub-skills as mentioned in Table 2. The results obtained for tasks 1 and 2 were validated by both Abbreviated Torrance test and Guilford Alternative Uses test.
Table 2. Creative Tests To Assess Design Sub-skills

\begin{tabular}{|c|c|c|}
\hline Task & Sub-skill(s) & Test \\
\hline \multirow{4}{*}{ Task $1 \& 2$} & Fluency & \multirow{4}{*}{$\begin{array}{l}\text { (i) Abbreviated Torrance Test } \\
\text { (ii) Guilford Alternative Uses }\end{array}$} \\
\hline & Flexibility & \\
\hline & Originality & \\
\hline & Detailability & \\
\hline Task 3 & Abstractability & Meekers Test \\
\hline
\end{tabular}

The fluency (based on total number of ideas) and flexibility (based on distinct ideas generated) were identified from their corresponding normalized scores. In case of measuring originality two different originality scores are computed (mean originality and maximum originality). Mean originality is the average scores of all the ideas, while maximum originality score corresponds to the best idea. It should be noted that it is the best idea one is interested in rather than the number of ideas.

The formula used to determine the originality score ' $\mathrm{S}$ ' for idea ' $i$ ' is

$$
\mathrm{Si}=9\left\{\begin{array}{c}
\% \mathrm{H}-\% \mathrm{C}\} \\
\% \mathrm{H}-\% \mathrm{~L}
\end{array}\right.
$$

where $\% \mathrm{H}$ is highest frequency, $\% \mathrm{C}$ is frequency of idea and $\%$ is lowest frequency

For measuring abstractability, each similarity provided was given 1 point, while responses that are found rarely were given 2 points. The total is obtained by summing up all the points for all questions. Based on the extent of minute details incorporated / elaboration in the solution, detailability is measured. Measuring the level of fixation is a complex task as fixation can occur in many ways. For the present study, fixation to example solution as well as to favourite toy was considered. A mathematical formula is developed to find the normalized score of fixation.

$$
\mathrm{F}=\mathrm{f}_{1}+\mathrm{f}_{2}
$$

where ' $F$ ' is the overall fixation level, ' $\mathrm{fl}$ ' is fixation due to example solution and ' $\mathrm{f} 2$ ' is fixation due to favourite toy or last played toy. Fixation due to example solution can be computed using the formula

$$
f_{1}=[1.5(x)+4(p)]
$$

where $x$ is the number of similar physical attributes and $p$ is the number of similar functional principles. The example solution provided to the experimental group consisted only one functional principle (musical instrument) and four attributes viz., keyboard with Braille, speaker, recording facility and a mike. A weightage of 1.5 is given for each attribute copied from the example solution, accounting to a maximum of 6 points and for the functional principle copied; a weightage of 4 is considered. The authors chose a scale of $1-10$, with ten being the maximum 
level of fixation. Further, similar functional principles are given more weightage than physical attributes. This is because copying the physical attributes causes less fixation compared to copying functional principles.

Fixation due to favourite toy can be computed using the formula

$$
\mathrm{f}_{2}=6 / \mathrm{n}(\mathrm{x})+4
$$

where ' $n$ ' is the total number of physical attributes his/her toy may have and ' $x$ ' is the number of physical attributes copied.

\section{Results And Discussion}

To ensure reliable data for analysis, the sample solutions that deviated from the prior instructions were not considered. This has increased the sanctity of the data. To ensure reliable and uniform scoring method, a set of instructions has been drafted for the evaluators. Two evaluators have graded the responses from the students independently. A crosscheck of grades is performed against each other to check for any bias or inconsistency. In case of any bias or inconsistency, the response sheet is forwarded for third evaluation. Figure 1 shows a typical sample solution provided by one of the participants for task 1 , wherein the scores of fluency, flexibility, originality and detailability are high.

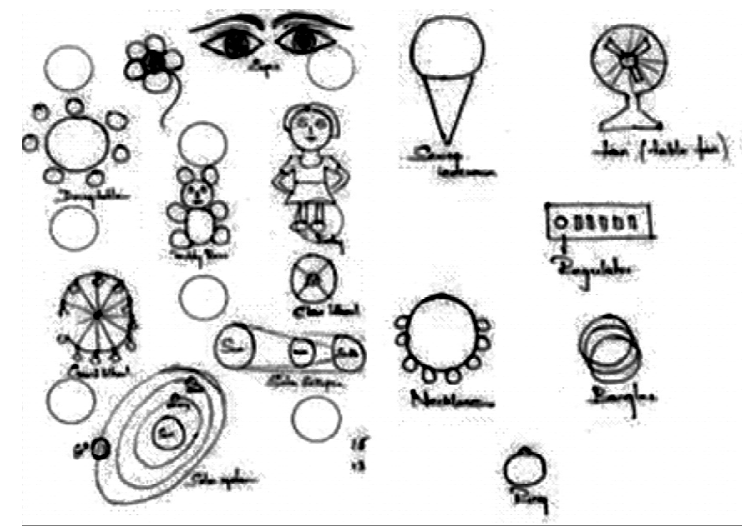

Fig 1.Sample solution to task 1 provided by one of the participant

The following observations can be inferred from the analysis:

a. Flexibility and originality correlate well i.e. the students who have high flexibility possess high originality. This is because students with high originality can produce multiple solutions to a given task leading to higher flexibility.

b. Detailability and afixability also correlate well. The students who have provided more elaborative solutions were found to be less fixated. c. Fluency and originality show a weak correlation. Though the quantity of ideas is more, it does not yield to high original score.

d. In response to task 4, a large percentage of students have shown fixation either due to example solution provided or their favourite toy.

e. Afixability and originality score were found to be high in case of control group whereas fixation group has shown a higher fluency score.

f. Majority of the students have shown a low originality score and high levels of fixation, students of IIT Kharagpur being an exception.

g. The above phenomenon is found to be consistent in all the institutes where the study was conducted.

h. In the present study, only intrinsic validation has been done. Detailed validation of the tests requires collection of large data across the country.

i. This skill analysis may have potential uses in determination of design strengths/weaknesses of Indian engineering students for the purpose of continuous improvement and evaluation of the curriculum.

j. This study is a necessary prerequisite for creating a framework for future experiments related to analysis of design skills, to establish new grading techniques for design classes and curriculum evaluation.

k. Figure 2 shows the normalized scores of various DT sub-skills among the IIT students. The DT skills of students from IIT were found to be high when compared to students from other Institutes. Perhaps this variation could be due to the academic background of the students, curriculum offered by the Institute and teaching paradigm.

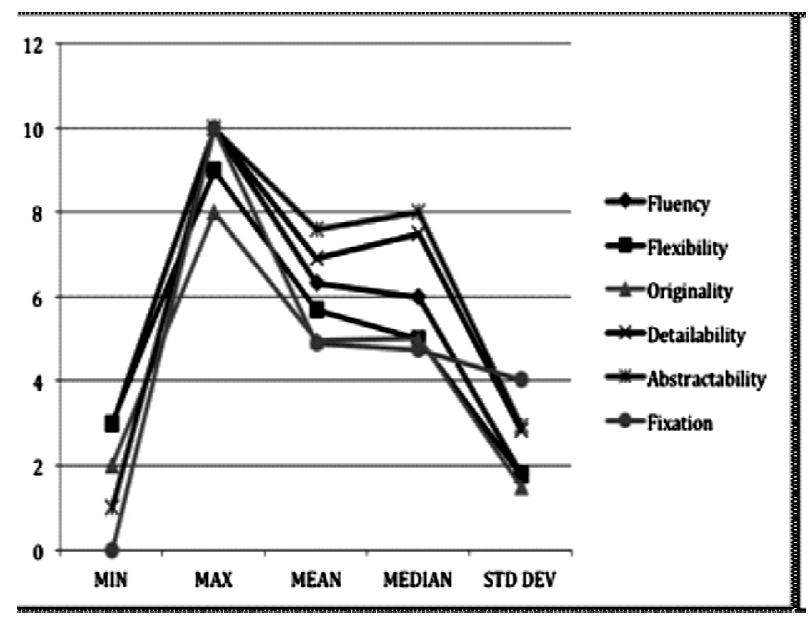

Fig 2.Normalised scores of various sub-skills among IIT students 


\section{Conclusions}

The various DT skills of Indian engineering students were analyzed using standard creative tests and the results are presented. It is observed that, the findings of the present work are similar to the earlier reports quoted [3-5] except that the fixation levels of Indian engineering students are higher. The results indicate the need for modifying the teaching paradigm for engineering education to increase the emphasis on innovation and creativity in the curriculum, which is currently being studied by the authors. The present work is being planned to extend to other design skills as well. Plans are also underway to conduct the task in some more Institutes / Universities to observe the variation on a large sample as well as to validate the results.

\section{Acknowledgments}

The authors would like to acknowledge the support of the Department of Science and Technology, New Delhi under Grant No: SR/CSI/130/2011(G) to carry out the present research. The authors thank the Management / Director / Principal / Dean / Head of the Institutes / Universities / Departments for providing conducive environment to carry out the task at their place. The authors also acknowledge the support of the Management, Director and Principal of SR Engineering College (A), Warangal in carrying out this research work.

\section{References}

[1] H. Herzberger, "Lessons for Student in Architecture", Rotterdam, Uitgeverij, 1991.

[2] C. Eckert, M. Stacey, "Sources of inspiration: a language of design", Design Studies, vol. 21, pp. 523-538, 2000.

[3] J. Shah, R.E. Millsap, J. Woodward, S. M. Smith, "Applied Tests of Design Skills-Part 1: Divergent Thinking", Journal of Mechanical Design, vol. 134, pp. 021005-1 - 021005-10, 2012.

[4] J. Shah, "Identification, Measurement and Development of Design Skills in Engineering Education", International Conference on Engineering Design (ICED05), Melbourne, Australia, 2005.

[5] J. Shah, S. M. Smith, J. Woodward, "Development of Standardized Tests for Design Skills", International Conference on Engineering Design (ICED09), Stanford, CA, 2009.

[6] S. Klausen, "The notion of creativity revisited: A philosophical perspective on creativity research" Creativity Research Journal, vol. 22(4), pp. 347360, 2010.

[7] R.E. Franken, "Human motivation", (4th ed.), Belmont, CA US: Thomson Brooks/Cole Publishing Co., 1998. 